\title{
Study on Ablation Wear of Gun
}

\author{
Jianjie Zhu ${ }^{1, a)}$,Liping Zheng ${ }^{1, b)}$,Yingxiu Cao ${ }^{1, c)}$ \\ 1 Mechanical Engineering College, Shijiazhuang 050003, China. \\ a)2451396862@qq.com, b)13191885181@163.com, c)305656641@qq.com
}

Keywords: Ablation, Wear, Life expectancy, Life extension.

\begin{abstract}
Artillery barrels gradually ablate wear and tear in the shooting process, which reduced its internal ballistic performance and severely limited the artillery power and service life. In this paper, the mechanism of gun's ablation and wear is analyzed from three aspects: heat factor, chemical factor and mechanical factor. And the existing ablation wear problem analysis method was compared, which can provide an important reference for predicting and extending the life of the tube.
\end{abstract}

\section{Introduction}

Artillery tube ablation and wear is a complex phenomenon acting on the tube bore, where heat, mechanical, chemical and other factors work at the same time when the pellet is launched. During the shooting process, these two kinds of destructive effects exist at the same time. The result of its comprehensive effect is that the bore's diameter increases to varying degrees in the axial position of the whole bore, resulting in the changes of artillery ballistic start conditions. It will have a great impact on the use of artillery performance and the shooting accuracy ${ }^{[1]}$. Therefore, we need to deeply analyze the causes, processes, mechanisms of damages on artillery bore structure caused by ablation wear, so as to put forward the corresponding anti-ablation, anti-wear technical measures to improve the life of the barrel.

\section{Artillery Barrel Ablation Mechanism}

At present, there are more consistent conclusions about the ablation mechanism of artillery barrels. It is believed that ablation is the result of a combination of thermal-chemical-mechanieal. The ablation mechanism has been confirmed and developed by many researchers. Figure 1 depicts the ablation mechanism of the tube under the firing environment. It comprehensively considers the influence of three factors on ablation, and systematically expounded the partition, process, product and mechanism of ablation ${ }^{[2]}$. 


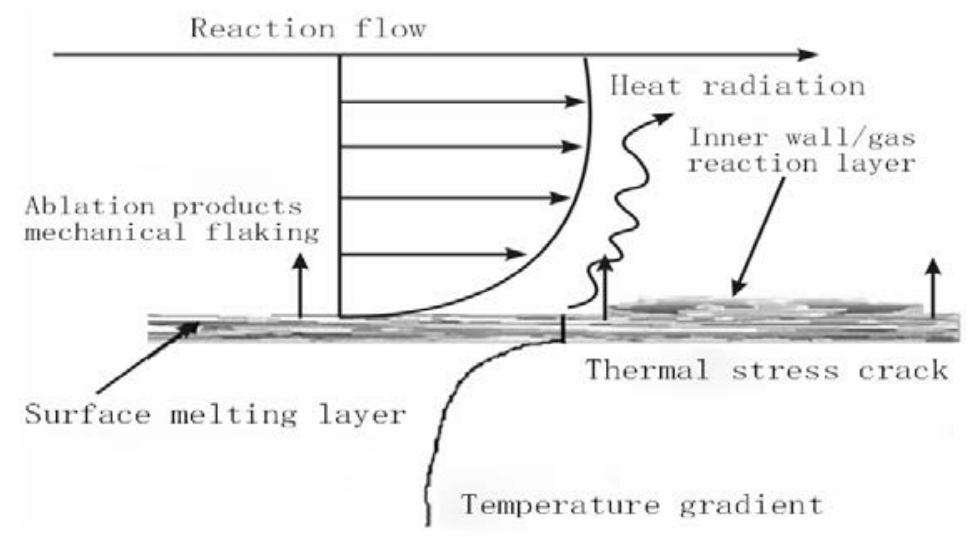

Figure 1. Tube ablation model.

\subsection{Heat ablation}

Among the various factors that cause damage to the inner chamber, the heat effect is the primary and fundamental. The individual effects of the heat factor can lead to three kinds of failure phenomena: the thermal softening of the body surface; the thermal transformation of the bore wall; the melting of the surface. When the gun is fired, the volume of the material on the surface of the chamber is alternately expanded and contracted by rapid heating and cooling, and a sharp phase change occurs at the same time. The high temperature environment provides favorable conditions for the chemical reaction between the gunpowder gas and the metal in the borehole wall. The resulting white layer, such as Fe3C, will melt under heat and be removed by high-speed gunpowder gas to accelerate the inner chamber failure process. Melting ablation is the fastest and most severe ablation mechanism that causes the inner bore to be destroyed, which is particularly pronounced in high-bore large caliber artillery. Meanwhile, the heat can also cause the tube thermal stress, thermal bending and other undesirable phenomena, which affect the use of artillery performance on some degree. So the heat problem has aroused people's attention for a long time, and becomes a necessary factor in the design of artillery.

\subsection{Chemical ablation}

The main process of chemical ablation is carburizing and oxidation. In the process of carburizing, the carbon spread from gas to the inner wall of the bubble and with the base metal to form solid solution. Excessive carbon promotes the precipitation of cementite, thereby reducing the toughness and melting point of the bore, resulting in the substrate being easily eroded by heat and mechanical factors. Similar to carburization, oxygen in the gunpowder gas can spread to the metal surface and oxidize it. Iron oxide will form a brittle surface of the flaky, easily formed into hot cracks and then be corroded. Besides carburizing and oxidation, many researchers suggested that hydrogen corrosion, hydrogen embrittlement and hydrogen induced cracks also play an important role in the ablation process. Underwood ${ }^{[3]}$ compares laser pulse ablation with actual ablation of the sample and then found that laser pulse heating well simulated the actual ablation status in the coating hot melt, hot cracking and other aspects. However, the cracks in the base metal covered by the coating can't be imitated. They think this is because there is hydrogen cracking in the actual ablation. Sopok $^{[4]}$ believes that the hydrogenation process is that the diffusion of hydrogen in the gun steel reduces the strength and toughness of the steel, and increases the risk of cracking and brittle failure. When hydrogen is absorbed through the unoxidized crack surface, the surface energy required for crack propagation is reduced. 


\subsection{Mechanical wear}

After the heat and the chemical effect, the base metal is prone to heat softening, mechanical strength and crack, etc. The friction generated during the coupling process is sufficient to consume the part of the matrix material. This is the main way of mechanical wear. In addition, due to unburned propellant particles and the high-speed movement of the peeling produced by ablation, the mechanical erosion of the bore is also great.

\section{Analysis of ablation wear problems}

The ablation behavior of the barrel is an extremely complicated process. It is very difficult to completely simulate the ablation wear when the gun is fired. The roughness of the pipe can be simplified and the physical parameters can be selected for simulation.

\subsection{Empirical method}

The empirical equation used to predict the barrel wear rate can be divided into two categories. The first is based on the correlation between the bore wall temperature and the measured wear rate. Lawton $\mathrm{B}^{[5]}$ studied the relationship between the amount of ablation of the uncoated tube and the maximum wall temperature in the bore, and the results are as follows:

$$
\mathrm{w}=\mathrm{At}_{0} \sqrt{\frac{\mathrm{T}_{\mathrm{i}}}{\mathrm{T}_{\mathrm{a}}}} \exp \left(\frac{-\Delta \mathrm{E}}{\mathrm{R}_{0} \mathrm{~T}_{\text {max }}}\right) \square \mathrm{Ta}=300 \mathrm{~K}
$$

Ablation coefficient A

$$
\mathrm{A}=114 \exp \left[0.02\left(\mathrm{f}_{\mathrm{CO}}-3.3 \mathrm{f}_{\mathrm{CO}_{2}}+2.4 \mathrm{f}_{\mathrm{H}_{2}}-3.6 \mathrm{f}_{\mathrm{H}_{2} \mathrm{O}}-0.5 \mathrm{f}_{\mathrm{N}_{2}}\right)\right]
$$

In the equation (1), $w$ is the ablation amount; $A$ represents the gunboat ablation, the value is between 20 and 200; $t_{0}$ is the time constant; $T_{a}$ is the set constant; $T_{i}$ is the inner chamber temperature before firing; $\Delta E$ represents the activation energy of the matrix metal, about $69 \mathrm{~kJ} / \mathrm{mol} ; R_{0}$ is the gas constant. $W$ and $T_{\max }$ are exponential, so the ablation amount is sensitive to the maximum temperature of the bore. The results of the simulation test and the live fire test showed that the temperature of the tube bore was reduced by $10 \%$ and the ablation rate was reduced by $300 \%$.

The second is to consider the internal trajectory factor, which is proposed by Iama ${ }^{[6]}$, as shown in equation (2). It includes muzzle velocity, barrel length, chamber pressure and load density, with particular regard to propellant factors and coolant factors.

$\mathrm{w}_{2}=\mathrm{w}_{1} \frac{\Delta_{2}}{\Delta_{1}} \sqrt{\frac{\mathrm{P}_{2}}{\mathrm{P}_{1}}} \frac{\mathrm{L}_{2} / \mathrm{V}_{2}}{\mathrm{~L}_{1} / \mathrm{V}_{1}}\left(\frac{\mathrm{V}_{2}}{\mathrm{~V}_{1}}\right)^{3}(\mathrm{PF})(\mathrm{CF})$

$W_{1}, \Delta_{1}, P_{1}, L_{1}, V_{1}$ indicates the wear, load density, pressure, length, and velocity of the reference tube. Correspondingly, $W_{2}, \Delta_{2}, P_{2}, L_{2}, V_{2}$ indicates the wear, load density, pressure, length, and velocity of the test tube. $\mathrm{PF}$ is the propulsion factor, and $\mathrm{CF}$ is the cooling factor.

Chung $^{[7]}$, based on Rauf Imam's empirical equation, presented an equation that accurately calculates the erosion rate of large-caliber cannon barrels, as shown below.

$$
\mathrm{w}_{2}=\mathrm{w}_{1} \mathrm{~K} \frac{\mathrm{V}_{2}{ }^{\mathrm{cV}}}{\mathrm{V}_{1} \mathrm{cV}_{1}}
$$


Where $\mathrm{K}=\frac{\Delta_{2}}{\Delta_{1}} \sqrt{\frac{\mathrm{P}_{2}}{\mathrm{P}_{1}}} \frac{\mathrm{L}_{2} / \mathrm{V}_{2}}{\mathrm{~L}_{1} / \mathrm{V}_{1}}(\mathrm{PF})(\mathrm{CF})$

In equation (3), $c$ is the empirical constant specific to the size of the barrel, for the $155 \mathrm{~mm}$ artillery, $c$ takes the value of 0.6 . Experiments on the erosion rate of different guns have shown that higher rates of erosion are usually associated with higher muzzle velocity, higher pressure and higher charge.

The empirical formula not only has a positive effect on the initial design of the artillery and the initial test, but also can quickly estimates the degree of abduction of artillery. Compared with the modeling analysis, the empirical equation is easier to predict.

\subsection{Calculation and analysis}

Conroy $^{[8]}$ coupled one-dimensional heat transfer model and one-dimensional two-phase intra-ballistic model to simplify the turbulence boundary layer. As the boundary layer is very thin, you can use the plate model to solve the boundary layer heat transfer coefficient, which according to one-dimensional thermal equation to find the wall temperature. The convective heat transfer coefficient of the simplified boundary layer is

$$
h=0.037 \frac{\mu}{X} \operatorname{Re}^{0.8} \frac{c_{f}}{c_{f_{t}}} c_{p}
$$

In equation (4), $X$ is the equivalent plate length. $C_{f} / C_{f_{t}}$ is the compressible surface factor. $R_{e}$ is the Reynolds number. $c_{p}$ is the specific heat capacity. The above parameters are a function of airflow velocity $\mu_{g}$, temperature $T_{g}$, density $\rho_{g}$, gas viscosity coefficient $\mu$. On the basis of this, the melt removal mechanism is used to further improve. The improved model is the coupling effect of hot melt, heat transfer, mass transfer and internal thermochemistry. $\mathrm{Li}^{[9]}$ referred to this model based on the theory of the melting layer, but did not consider the chemical reaction of the gunpowder gas, derived the thickness of the tube melting layer integral equation.

$\mathrm{S}(\mathrm{t})=\frac{\int_{0}^{\mathrm{t}_{1}} \mathrm{q}_{\mathrm{w}} \mathrm{d}_{\mathrm{t}}+\int_{0}^{\mathrm{t}_{1}} \lambda \frac{\partial \mathrm{T}_{\mathrm{s}}}{\partial_{\mathrm{r}}} \mathrm{d}_{\mathrm{t}}}{\rho \mathrm{L}}$

\section{Barrel life prediction and life extension technology}

Artillery ablation is closely related to barrel life. For the rifle gun, the serious wear area of the barrel generally occurs from the beginning of the rifling to about 10 times the length of the forward length. In this area, the gunpowder gas is scouring violently, and the inner diameter of the barrel is abruptly worn and the wear is serious. The radial wear $\Delta d$ of the bore can accurately characterize the trajectory performance change of the life cycle of the artillery, which can combine the conditions of the life of the gun. For an artillery in the service, the changes of internal and external ballistic performance are mainly due to radial wear. At the end life of the muzzle, it often appears that the initial velocity declines, the belt is flattened shooting spreads and so on. They are also caused by radial wear of the bore. Therefore, in the study of artillery ballistic performance changes and life cycle, this is a major factor, which has been confirmed in the relevant literature both at home and abroad.

In Reference [10], a multivariate linear regression method was used to study the correlation between $\Delta d$ and internal ballistic parameters. In Reference [11], the model of artillery based on LS-SVM is proposed, and the residual life evaluation model of artillery is established. In Reference [12], the calculation model of the initial velocity drop and the bore diameter of the borehole was established by using the classical inner trajectory theory, and the life of the barrel was predicted. In Reference [13], the life cycle of the gun barrel was predicted based on 
the gray linear regression model. The results show that the error between model predictive value and the measured value is relatively small. It can give useful reference for the military ordnance management department.

At present, the life of the gun barrel gets a certain increase by adding corrosion inhibitor to propellant and chroming in the chamber. However, it is still difficult to meet the needs of modern warfare. For this reason, People have made many useful attempts to improve the anti-ablation of artillery barrels. Such as tube bore laser heat treatment technology, composite barrel manufacturing technology, tube bore coating preparation technology. These technologies have made a great contribution to enhancing the life of the barrel ${ }^{[14]}$.

\section{Summary}

In the process of firing guns, the barrel of the tube withstands severe ablation erosion and wear, which has a direct impact on the firing rate of guns and life. Therefore, on the basis of studying the mechanism of ablation and ablation of the tube, it is necessary to analyze the existing ablation wear problem, establish the mathematical model of $\Delta d$ and the initial velocity descent or the number of warheads to predict the life of the barrel. And applying the relevant extension technology to the maintenance of old guns and the production of new guns is what we want to see.

\section{References}

[1] Xifa Zhang, Xinghua Lu. Interior ballistics of erosion guns[M]. National Defense Industry Press, Beijing, 2001.

[2] Xiaomin Peng, XIA Changqing, WU Anru, third ed.,Development of the ablation behavior and protection of gun barrel[J]. Journal of Sichuan Ordnance, 2014(1):68-72.

[3] UNDERWOOD J H, PARKER A P, VIGILANTE G N, third ed., Thermal damage, cracking and rapid erosion of cannon bore coatings[J]. Journal of Pressure Vessel Technology, 125(2003)299-304.

[4] SOPOK S, RICKARD C, DUNN S. Thermal-chemical-mechanical gun bore erosion of an advanced artillery system part one: theories and mechanisms[J]. Wear, 258(2005)659-670.

[5] Lawton B, Laird M. Influence of Gas Leakage on Heat Transfer and Wear in Gun Barrels[R]. US. : In $16^{\text {th }}$ International Symposium on Ballistics, 1996.

[6] Rauf Imam, An Empirical Approach to Predicting Cannon Tube Erosion Rate, AD-786 531, Benet Weapons Lab., August 1974.

[7] Dong-Yoon Chung, Myoungho Oh. New empirical method to enhance the accuracy in the erosion prediction of cannon tube[J]. Wear, 255(2003)98-101.

[8] Paul J Conroy. Gun Tube Thermal Management[R]. U.S.: U.S. Army Ballistic Research Laboratory. M D 21005.1993.

[9] Mingtao Li, Wanshan Cui, Zhe Yao, third ed., Prediction method of barrel life based on inner side meltoing theory[J]. Journal of gun launch \& control. 2009(1):5-8.

[10] Guijun Tian. Research on the wear and erosion of bore and its influence to interior ballistic performance[D]. Nanjing, 2003.

[11] Guojie Kong, Peilin Zhang, Longtang Xu, third ed., A new prediction model of decreasing quantity of gun muzzle velocity[J]. Journal of Ballistics, 2009,21(3):65-68.

[12] Jianpin Fu, Peilin Zhang, Guozhang Li. Gun tube life analysis and computation[J]. Journal of Ordnance Engineering College, 2000,45(1):6-10.

[13] Xiangfei Meng, Changming Wang, Boxia He, third ed., Prediction of Gun Barrel Life Based on Grey-linear Regression Combined Model[J]. Journal of Nanjing University of Science and Technology, 2012,36(4):635-638. 
[14] Yongcai Chen, Quizhi Song, Jianzhong Wang. New Technologies to Extend the Erosion Life of Gun Barrel[J]. Acta Armamentarii, 2006,27(2):330-333. 